\title{
EXPERIMENTAL ANALYSIS OF THE TENSILE PROPERTIES OF PAINTING CANVAS
}

\author{
Željko Penava ${ }^{1 *}$, Diana Šimić Penava ${ }^{2}$, Marijana Tkalec ${ }^{1}$ \\ ${ }^{1}$ University of Zagreb, Faculty of Textile Technology, Prilaz b. Filipovića 28a, Zagreb, Croatia \\ ${ }^{2}$ University of Zagreb, Faculty of Civil Engineering, Kačićeva 26, Zagreb, Croatia \\ E-mail: zpenava@ttf.hr
}

\begin{abstract}
:
In this paper, the practical application of uniaxial testing of painting canvas for determining its mechanical properties is presented. Painting canvases have a complex composite structure whose mechanical properties are considerably improved in relation with the initial basic material. Painting canvas or coated fabrics are obtained by applying a certain number of coatings to raw fabrics. Experimental testing and determining mechanical properties of painting canvas under tensile force at different angles in relation to the weft direction are discussed in the paper. The fabrics were tested before coating, as well as after one, two and three coatings. The values of tensile force in relation to relative extension of coated textiles were measured, as well as breaking force values, elongation at break, contraction at break, work to rupture. Based on the experimentally obtained values, modulus of elasticity, Poisson's ratio and the level of anisotropy of the coated textile materials were calculated. The experimental results demonstrate the applicability of theoretical formulae. The number of coated layers on the raw fabric exerts a significant impact on the Poisson's ratio. The values of breaking force, elongation at break, work to rupture and modulus of elasticity increase with an increase in the number of coated layers, and at the same time coefficient of anisotropy decrease. It has been shown that by increasing the number of coated layers in a coated material, its anisotropic properties decrease, while isotropic properties increase. With an increase in the number of coatings, the differences between experimental and theoretical values of modulus of elasticity decrease.
\end{abstract}

\section{Keywords:}

painting canvas, anisotropy, modulus of elasticity, breaking force, elongation at break, Poisson's effect

\section{Introduction}

Textile materials (fabrics, knits, nonwoven textiles) are generally inhomogeneous, anisotropic and discontinuous objects. Nowadays, the use of textile materials in different industrial branches is on the rise, especially in composite materials, and therefore the knowledge of their physical and mechanical properties is very important. In order to significantly improve the initial mechanical properties of textile materials, certain coatings are applied to the basic textile material on one or both sides in one or more layers. This results in a coated textile fabric whose properties are considerably improved in relation to the initial basic material and which can be used for special purposes. The fabric becomes more rigid by the process of coating. The coating has got its specific properties and fills the spaces between the yarns and „cements" warp and weft into one unit. Mechanical properties of the yarns are changed, and the rotation between the yarns is prevented.

Testing of coated textile materials relate to their physical and mechanical properties: stress, deformation, breaking force, elongation at break, modulus of elasticity, impermeability. Previous studies related to the mechanical properties of canvases are not extensive because of the complexity of the problem and do not provide systematic information on these properties $[5,10,11,25]$. This is because it is difficult to obtain repeatable measurement data due to the inherent stochastic nature of canvas.
Painting canvas can be defined as a composite structure consisting of a series of heterogeneous polymer layers. Structural properties of woven material in canvas are the result of a combination of numerous factors. This includes: fibre type, fibre strength, number of fibres in the yarn, fibre and yarn fineness, yarn twists, density of warp and weft yarns, weave pattern, crimp, woven fabric cover, treatments after weaving, treatments before painting or coating. Friction between fibres and on the fibre intersections, curvature of bending properties of the yarn has an effect on fabric properties. The interaction between all these factors affect the final behaviour of textiles in the diagram load-extension of the fabric weft and warp under the action of tensile forces. Describing the geometry of weave and mechanical properties of individual yarns, theoretical models to predict the mechanical properties of materials have been developed. The basic model, which supports many complex models that are still used today for testing and determining the mechanical properties, was developed by Pierce [23]. This was later elaborated by Kawabata [12], Hearle and associates [9], Greenwood [8] and Warren [30] by combining the geometrical and mechanical analysis. Pan gave more realistic predictions of fabric strength by including yarn interaction [21], while Kilby treated the woven material as a laminate of continuum [13] and he expanded the model to nonlinear, and also included dependability of mechanical properties on time, which is very important for realistic canvas modelling. Fabric research within fibre reinforced composites was also conducted [18]. When measuring, there are a number of factors influencing 
fabric mechanical properties: nonlinear viscoelasticity, friction between the fibres, yarns in fabrics, deviations in the density of the fabric, geometrical changes of weaves during the action of external forces, as well as a change in temperature and humidity [10]. Characteristics which may be relevant to canvas supports include: anisotropy, nonlinear stress-strain curve, creep, previous loads which influence stress-strain diagram [4, 14, 22]. Within conservation, most of the above characteristics have been suggested as relevant factors [27, $11,19]$. Very little in-depth research has been carried out to clarify which characteristics occur, or have a significant effect on the behaviour of easel paintings

Uniaxial testing is most commonly performed in conservation using either commercial or custom-designed instruments. Uniaxial rigs can be adapted for biaxial testing, offering a costeffective way of using standard equipment. There is, however, a restriction on the loading conditions that can be applied. Results from the biaxial tensile tester show that all the above characteristics can be observed in canvas supports and emphasize why a consistent, integrated theory to describe easel painting mechanics has not, as yet, been developed [31].

When the action angle of the external load (tensile force) changes, the elastic constants change too. Many researchers have dealt with this issue over the years, and many complex measuring systems for measuring different mechanical properties of fabrics have been constructed $[32,33]$. Uniaxial extension is the most widely spread procedure of testing and analysing physical and mechanical properties of textile products [2]. The most commonly performed method for measuring anisotropic tensile properties of fabrics is called "uniaxial test method" or the method of force action in only one direction. Kilby [13] was among the first to start studying and measuring fabric tensile properties under the action of tensile load in an arbitrary direction. He defined the Poisson's ratio and noticed there was a connection between the Poisson's ratio, shear modulus and modulus of elasticity. The influence of the Poisson effect on certain mechanical properties of fabrics, such as draping and shearing, is mentioned in the literature [1, 3 , 34]. The researchers determined the Poisson's ratio in the warp and weft direction based on geometric fabric model, and in that process excluded the influence of the yarn's Poisson's ratio. This led to the conclusion that the Poisson's ratio in fabrics comes out of the interaction between the warp and weft, and can be expressed in terms of structural and mechanical system parameters [17]. Due to the anisotropy of fabric, analysis of the influence of physical parameters of fabric on Poisson's ratio values is useful and provides a better explanation for certain fabric behaviours.

Theoretical analysis of coated fabrics [27] is often very complex due to its anisotropic properties, since along the anisotropy of the basic material there is a whole set of questions relating to the connections between the substrate and the coated layers, so the experimental check of the theoretical predictions is more important in those layers than in other materials. The functional connection between stress and strain cannot be determined theoretically, only experimentally by testing some specific material samples. Experiments on the extension of the coated fabric sample under static load will be performed. This testing will provide the most of data on mechanical material properties (fabrics). Anisotropy of raw canvas, raw canvas with insulation and 1,2 and 3 priming layers in relation to mechanical properties: breaking force, elongation at break, contraction at break, work to rupture and initial module of elasticity are tested on fabric samples which are cut at different angles to the weft direction. The initial module of elasticity can be predicted theoretically by developing a mathematical equation from the anisotropic effect of coated fabrics. Additionally, due to anisotropy of the canvas the Poisson's ratio changes in the process of canvas elongation. The influence of coating on the values of the Poisson's ratio has been researched too.

\section{Theoretical basis of anisotropic materials}

It should be noted that mechanical properties of coated fabrics firstly depend on their physical properties and the cutting direction of the sample (the direction of force activity). In terms of the structural characteristics, fabrics are described as elastic orthotropic materials at very small deformation which are defined as orthotropic plates with two mutually perpendicular planes of elastic symmetry $[16,7]$. These planes of elastic symmetry are planes of orthotropy. The x-axis is in the weft direction, and the $y$-axis is the warp direction of fabric, Figure 1.

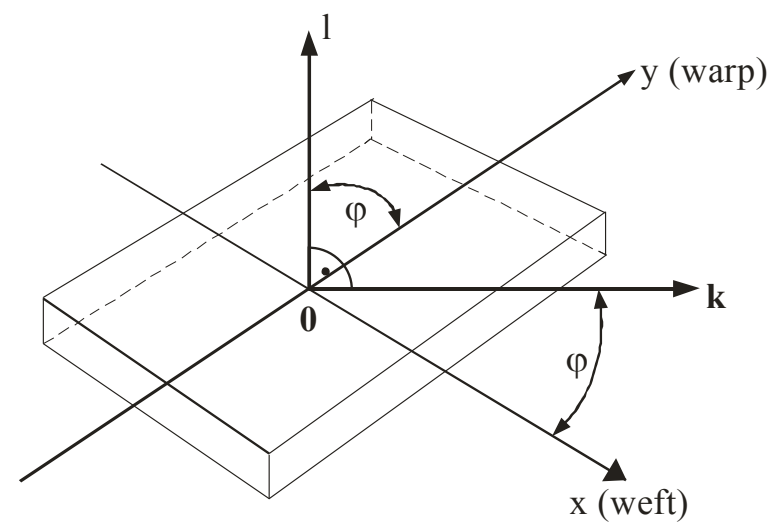

Figure 1. Element of the orthotropic plate - woven fabric

The stress in different directions is approximately linear with strain before the yield point. For the plane state of stress of an elastic, homogeneous, isotropic material in a linear region Hooke's law in the tensor form can be applied:

$$
\varepsilon_{i j}=S_{i j k l} \cdot \sigma_{i j}
$$

Equation (1) represents the matrix form of Hooke's law. $\varepsilon_{i j}, \sigma_{i j}$ are the strain and stress tensor components, and $S_{i j k l}$ is the elasticity tensor component. Taking into account symmetry and orthotropy, and resuming it to a plane problem, Hooke's law for an orthotropic and elastic material when the axis $k, I$ does not coincide with the axis $x, y$ of orthotropy, the anisotropic behaviours under tensile loads can be written in the matrix form [26]: 


$$
\left\{\begin{array}{c}
\varepsilon_{k} \\
\varepsilon_{l} \\
\gamma_{k l}
\end{array}\right\}=\left[\begin{array}{ccc}
\frac{1}{E_{k}} & -\frac{v_{l k}}{E_{k}} & \alpha_{k} \\
-\frac{v_{k l}}{E_{l}} & \frac{1}{E_{l}} & \alpha_{l} \\
\alpha_{k} & \alpha_{l} & \frac{1}{G_{k l}}
\end{array}\right] \cdot\left\{\begin{array}{l}
\sigma_{k} \\
\sigma_{l} \\
\tau_{k l}
\end{array}\right\}
$$

$\sigma_{k}$ and $\sigma_{l}$ are normal stresses, $T_{k l}$ is shear stress, $\varepsilon_{k^{\prime}}, \varepsilon_{l}$ are normal strain (relative extension strain), $\gamma_{k l}$ is shear strain (relative angle strain), $E_{k}, E_{l}$ are modulus of elasticity, $G_{k l}$ is shear modulus, $\alpha_{k}, \alpha_{1}$ are elasticity coefficients, $v_{k p}, v_{l k}$ are Poisson's ratio for arbitrary coordinate system $k, l$.

\subsection{Initial modulus of elasticity}

It is assumed that load extension curve for woven fabric is an approximate straight line before yield point. Therefore, elastic performance equation can be applied here. For orthotropic elastic materials modulus of elasticity $E_{k}, E_{p}$, for an arbitrary direction of tensile force action, i.e. in the coordinate system $k$, I whose axes does not coincide with axes $x, y$, is obtained by using the expression for the transformation of the elastic constants, which state [25]:

$$
\frac{1}{E_{k}}=\frac{\cos ^{4} \varphi}{E_{x}}+\frac{\sin ^{4} \varphi}{E_{y}}+\left(\frac{1}{G_{x y}}-\frac{2 \cdot v_{x y}}{E_{y}}\right) \cdot \cos ^{2} \varphi \cdot \sin ^{2} \varphi,(3)
$$$$
\frac{1}{E_{l}}=\frac{\sin ^{4} \varphi}{E_{x}}+\frac{\cos ^{4} \varphi}{E_{y}}+\left(\frac{1}{G_{x y}}-\frac{2 \cdot v_{x y}}{E_{y}}\right) \cdot \cos ^{2} \varphi \cdot \sin ^{2} \varphi,
$$

$\varphi$ is an angle between the stretching direction and axis $x$ (Fig. 1), $E_{x}, E_{y}$ are modulus of elasticity in two main directions (weft direction $\varphi=0^{\circ}$, warp direction $\left.\varphi=90^{\circ}\right) ; G_{x y}$ is shear modulus between both principal directions; $v_{x y}$ is the longitudinal Poisson's ratio (when the fabric is stretched in the warp direction). Due to the values of trigonometry functions at complementary angles $E_{k}$ equals $E_{l}\left(E_{k}=E_{l}\right)$. For this reason all further analysis will only focus on the modulus of elasticity $E_{k}$ which will be marked by $E_{\varphi}$. The modulus of elasticity $E_{\varphi}$ in any given stretching direction can be calculated by the following equation:

$$
\frac{1}{E_{\varphi}}=\frac{1}{E_{k}}=\frac{\cos ^{4} \varphi}{E_{x}}+\frac{\sin ^{4} \varphi}{E_{y}}+\left(\frac{1}{G_{x y}}-\frac{2 \cdot v_{x y}}{E_{y}}\right) \cdot \cos ^{2} \varphi \cdot \sin ^{2} \varphi
$$

Numerical values of $E_{x}, E_{y}, G_{x y}$ and $v_{x y}$ can be obtained by the experimental measurement of a canvas sample in the laboratory. However, $G_{x y}$ and $v_{x y}$ are too complicated to measure in normal experimental conditions. For this reason, it is proposed that shear modulus $G_{x y}$ and Poisson's ratio $v_{x y}$ can be replaced by the modulus of elasticity $E_{45^{\circ}}, E_{x}$ and $E_{y}$ whose values are more easily measured in the laboratory during the uniaxial extension of coated fabric when tensile forces act in directions $\varphi=0^{\circ}, 45^{\circ}, 90^{\circ}$. When tensile force acts under an angle of $\varphi=45^{\circ}$, the expression for $E_{45^{\circ}}$ is obtained by using equation (5):

$$
\begin{aligned}
& \frac{4}{E_{45^{\circ}}}=\frac{1}{E_{x}}+\frac{1}{E_{y}}+\left(\frac{1}{G_{x y}}-\frac{2 \cdot v_{x y}}{E_{y}}\right) \\
& \left(\frac{1}{G_{x y}}-\frac{2 \cdot v_{x y}}{E_{y}}\right)=\frac{4}{E_{45^{0}}}-\frac{1}{E_{x}}-\frac{1}{E_{y}}
\end{aligned}
$$

By substituting equation (6) into equation (5) we get:

$$
\frac{1}{E_{\varphi}}=\frac{\cos ^{4} \varphi}{E_{x}}+\frac{\sin ^{4} \varphi}{E_{y}}+\left(\frac{4}{E_{45^{\circ}}}-\frac{1}{E_{x}}-\frac{1}{E_{y}}\right) \cdot \cos ^{2} \varphi \cdot \sin ^{2} \varphi
$$

Equation (7) indicates the mathematical relation between the modulus of elasticity in any given direction and $E_{x}=E_{0^{\circ}}, E_{y}=E_{90^{\circ}}$ and $E_{45^{\circ}}$

Due to the variation in values of breaking force $F_{\varphi}$, elongation at break $\varepsilon_{\varphi}$, work to rupture $W_{\varphi}$ and initial modulus of elasticity $E_{\varphi}$ in different directions, coefficients of anisotropy $K_{A i}\left(K_{A F}\right.$, $K_{A \varepsilon}, K_{A W}$ and $K_{A E}$ ) are defined so that the level of ansiotropy could be determined as precisely as possible. Determining the coefficients of anisotropy $K A i$ is given in equation (8):

$$
K_{A i}=\frac{i_{\max }}{i_{\min }}, \quad i=F, \varepsilon, W, E
$$

where: $i_{\text {max }}, i_{\min }$ are the highest, that is the lowest value of the mentioned property.

For isotropic materials the coefficient of anisotropy is equal to one $\left(\mathrm{K}_{\mathrm{i}}=1\right)$ which indicates that physical and mechanical properties, force and strength in different directions are equal. Due to variations of physico-mechanical properties of materials, breaking forces, etc., in different directions the coefficient of anisotropy increases and is greater than one $\left(K_{i}>1\right)$ for anisotropic materials. Materials, in which anisotropy is more expressed, have a higher value $\mathrm{K}_{\mathrm{i}}$ (i.e. the range of measured values between the highest and lowest values increases).

\subsection{Uniaxial contraction}

When a fabric is stretched in one direction, it tends to contract in the direction perpendicular to the direction of stretch. The yarns in the direction of tensile force are flattened out (extended), and in the orthogonal or nonloading direction the yarns have a longer geometrical path to "curve around". Because there is no limiting force, waviness (amplitude) of the yarn in vertical force direction increases. This results in a dimension reduction of the fabric width. This phenomenon is called Poisson effect. Poisson's ratio, a measure of the Poisson effect, is the ratio of the relative contraction strain to the related extension strain in the direction of the applied load [28].

The researchers determined Poisson's ratio in the warp and weft direction of the fabric based on the geometric models of fabric and excluded the impact of Poisson's ratio on the yarn. In this way, they came to the conclusion that the Poisson's ratio of 
fabrics results from the interaction between the warp and weft, and can be expressed in terms of structural and mechanical parameters of the system [27]. Poisson's ratio is one of the fundamental properties of any structural material including fabric. To determine the Poisson's ratio of fabrics, devices for measuring tensile strength are used, and the coefficient is determined in the linear part of the diagram of Hooke's law. During testing the fabric to stretch, the initial length of the tested sample $I_{0}$ increases by $\Delta l$, and the final fabric sample length is $I$. The initial width of the fabric sample $b_{0}$ decreases by $\Delta b$ and the final sample width is $b$.

Absolute longitudinal strain (absolute extension strain):

$$
\Delta l=l-l_{0},
$$

Absolute transverse strain (absolute contraction strain):

$$
\Delta b=b-b_{0}
$$

Relative longitudinal strain (relative extension strain) is defined as:

$$
\varepsilon=\frac{\Delta l}{l_{0}} \cdot 100 \%=\left(\frac{l}{l_{0}}-1\right) \cdot 100 \%
$$

Transverse strain (relative contraction strain) is defined as:

$$
s=\frac{\Delta b}{b_{0}} \cdot 100 \%=\left(\frac{b}{b_{0}}-1\right) \cdot 100 \%
$$

The physical meaning of Poisson's ratio is shown by expression (13). Longitudinal and transverse strains have an opposite sign.

$$
v=\left|\frac{s}{\varepsilon}\right|=\left|\frac{l_{0}}{b_{0}} \cdot \frac{b-b_{0}}{l-l_{0}}\right| \quad, \quad s=-v \cdot \varepsilon
$$

In isotropic, homogeneous materials Poisson's ratio occurs in an interval from 0 to 0.5 .

The values of the Poisson's ratio for fabrics are different from those of standard engineering materials and they can reach values outside the mentioned range. When tensile force acts in one fabric direction, in this direction is the relative extension $\varepsilon$ of fabric, and in the direction perpendicular to force direction is the relative contraction of the fabric $s$. When the calculated values $\varepsilon$ and $s$, according to expressions (11) and (12), are put in the expression (13) the Poisson fabric effect $v$ is obtained. Due to fabric anisotropy Poisson's ratio changes during the process of fabric sample extension.

\section{Experimental part}

The experimental study of tensile properties was carried out by measuring the extension of linen (raw) fabrics and coated fabrics samples under the action of tensile force till rupture. Tensile force acts on the samples that are cut at different angles of $0^{\circ}, 15^{\circ}, 30^{\circ}, 45^{\circ}, 60^{\circ}, 75^{\circ}, 90^{\circ}$ to the direction of the weft. The values of tensile force in relation to relative extension were measured, as well as breaking force, elongation at break, contraction at break, work to rupture. For this purpose classical methods and instruments for testing tensile fabric properties were applied. Based on the experimentally obtained values, initial modulus of elasticity, Poisson's ratio and coefficients of anisotropy were calculated in various directions. For the extensions and tensile forces which act in the warp and weft direction, corresponding contraction strains of linen fabric and coated fabrics were scanned. The Poisson's ratio of canvas was calculated by using the testing results. The conducted experiment is used to determine the influence of coating and the number of layers on the degree of anisotropy, value of modulus of elasticity, Poisson's ratio, value of breaking forces, extensions at break and work to rupture.

\subsection{Coating procedures}

In painting technology, there are three basic elements equivalent to: colorant, binder and surface. The image is composed of the substrate on which there is a binder-applied colorant. The substrate is a prepared surface that forms the basis on which an artistic construction begins. It consists of a holder (surface on which it is possible to paint such as cloth, paper, glass, etc.) and base (preparation). Linen fabric as a substrate in art requires specific processing, including specific preparation. The negative influence of cellulose and other ingredients in linen yarn (apart from wax) on resistance, consistency and durability of linen weave can be decreased by the adequate preparation of the substrate and proper protection from the influence of negative factors. This is achieved by adequate insulation and canvas preparations, which can significantly influence the durability of the painting and extend its lifetime. Considering the fact that the linen fabric as a substrate is chemically active, it is first processed using the insulation method, that is, impregnation, which protects the ground, the fabric yarns from the effects of the binder which penetrates from the colour or preparation, Figure $2[5,6,29]$. All the more porous substrate types need to be insulated against excessive absorption, before applying preparation as well as protecting from negative properties of some organic binders on the substrate matter.

The basis of the painting (preparation or ground; prepared layer that is applied to the holder of the picture) is one of the fundamental elements of the image. The basics preparation or painting processes are applied to the surface holder in several layers on which the said prepared layer physically acts as an intermediary between the holder and the painted layer to ensure stability of the coat, protection against external influences and binders from dyes, and also enables tighter binding of the painting layers. Layer preparation or base or ground usually consists of binders and fillers.

The preparation coat is applied to the substrate of the painting, having a multiple function: reconstructing conditions for better binding the colour and binder to the base (substrate), insulation of porous substrates and protection from negative influences 


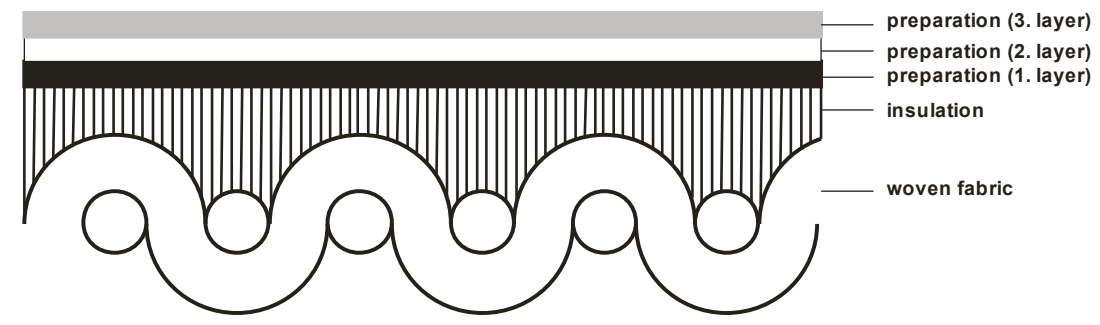

Figure 2. Schematic presentation of the canvas

of individual binders from the painted layer (oil, resin, etc.), regulation of binding matter absorption from the painted layer, as well as an adequate white pigment, that is colour. The durability of the canvas, as well as the painting, depends on the choice of filler and binder, their preparation and performance. A well-prepared canvas, being a painting base, should have the following properties: smooth surface, flexibility, elasticity of prepared canvas and neutrality of prepared canvas towards the upper colour layers [15].

The insulation that is the impregnation of linen canvas requires $500 \mathrm{ml}$ of $7 \%$ solution of animal glue which requires 35 grams of animal glue and $500 \mathrm{ml}$ of water.

Insulation procedure: The binder which will later be used as a preparation binder will be used as the insulation - animal glue.

In a small amount of water the glue swells about 8 hours, after which swelled glue starts to melt in a water bath at a temperature of $45^{\circ} \mathrm{C}$. The canvas is most often impregnated with a solution of animal glue $\left(45^{\circ} \mathrm{C}\right)$. Sizing with animal glue protects the canvas yarn from the effects of binder which penetrates from the colour or preparation. Also, the glue tightens the canvas and decreases the influence of moisture on the canvas. In order for the glue not to soak completely the yarn of the canvas and stiffen it after the drying process, the canvas can be previously moistened with cold water. To accelerate basics, it suffices to apply one coat of insulation [15].

In order to prepare the linen canvas (preparation of glue-chalk ground), $35 \mathrm{~g}$ skin glue, $500 \mathrm{ml}$ water, $350 \mathrm{~g}$ of filler (champagne chalk) and $175 \mathrm{~g}$ of bleach (titanium white pigment) are necessary. Preparation procedure: A solution of animal glue, which was already used for insulation (sizing), is heated to $45^{\circ}$, the filler is gradually mixed in, best by using a sieve, up to the moment when the surface of solution of animal glue is coated with a thin layer of filler. The solution saturated by the filler rests for some time so that all the air bubbles from the filler could come out, and then it is carefully mixed and strained through a highdensity sieve. The small holes on the dry layer of the preparation can occur due to excessive coating of the hot preparation. This preparation is applied using the tepid-coating method. If necessary, you may add white pigment to the preparation in ratio with the filler 1:2. Three layers of preparation are applied. After applying the first coat using a brush, the canvas is dried on air. Prior to applying the second coat, it is moistened with a wet sponge so that the binder from the second coating would not soak it, weakening it. The moves of the second layer are applied in the opposite direction (cross) of the moves of the first layer. The third layer is also applied in the opposite direction to the second layer upon drying of the same [15].

\subsection{Testing samples}

To carry out this study, four different samples were available. To study the mechanical properties of the painting canvases, a raw fabric (LO) in plain weave was selected. The raw material composition was $100 \%$ linen, the weft and the warp thread density was 15 yarns $/ \mathrm{cm}$, the weft and the warp yarn count was 100 tex, areal density was $262 \mathrm{~g} / \mathrm{m}^{2}$, and fabric thickness was $0.51 \mathrm{~mm}$. By applying insulation and one layer of preparation to the raw fabric, a testing sample (L1) was obtained. Its areal density was $386 \mathrm{~g} / \mathrm{m}^{2}$ and fabric thickness was 0.76 $\mathrm{mm}$. Afterwards, by applying insulation and two layers of preparation, a testing sample labelled as (L2) was prepared with $421 \mathrm{~g} / \mathrm{m}^{2}$ areal density and $0.83 \mathrm{~mm}$ fabric thickness. Finally, by applying insulation to the raw textile material and three layers of preparation a test sample labelled as (L3) was prepared, and its areal density was $453 \mathrm{~g} / \mathrm{m}^{2}$ and thickness was $0.89 \mathrm{~mm}$. Yarn count was determined by the gravimetric method according to standard ISO 2060:1994. The number of threads per unit length was tested according to standard ISO 7211-2:1984. Standard ISO 5084:1996 describes a method for the determination of the thickness of fabric. The initial state of test samples L0, L1, L2 and L3 was recorded with a digital microscope Dino-Lite model AM4113T with increasing 50x with LED reflected light, Figure 3.

For the purposes of testing tensile properties, standard samples with dimensions $300 \times 50 \mathrm{~mm}$ were cut and clamped in the clamps of the tensile tester at a distance of $10=200 \mathrm{~mm}$ and subjected to uniaxial tensile load till rupture. The pulling speed of the clamps was $100 \mathrm{~mm} / \mathrm{min}$.

The samples were cut in seven different directions: warp direction $\left(\varphi=90^{\circ}\right)$, weft direction $\left(\varphi=0^{\circ}\right)$, and at angles of $15^{\circ}$, $30^{\circ}, 45^{\circ}, 60^{\circ}, 75^{\circ}$ towards the weft, Figure 4.

Five tests were done on the tensile tester for each mentioned cutting direction of the sample. Tensile properties of all samples were tested in accordance with standard ISO ISO13934$1: 2008$ using the strip method for measuring fabric strength on a tensile strength tester. A tensile tester Statimat M German manufacturer "Textechno" was used for testing. This tensile tester is an automatic, microprocessor-controlled instrument operating on the principle of constant deformation speed. 

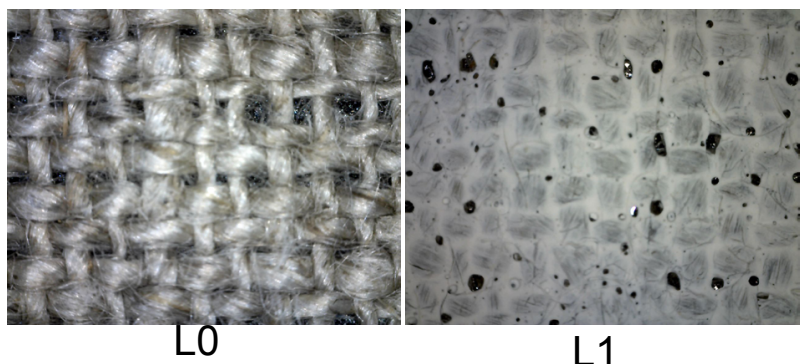

L1

Figure 3. Initial states of the testing samples with 50x increasing

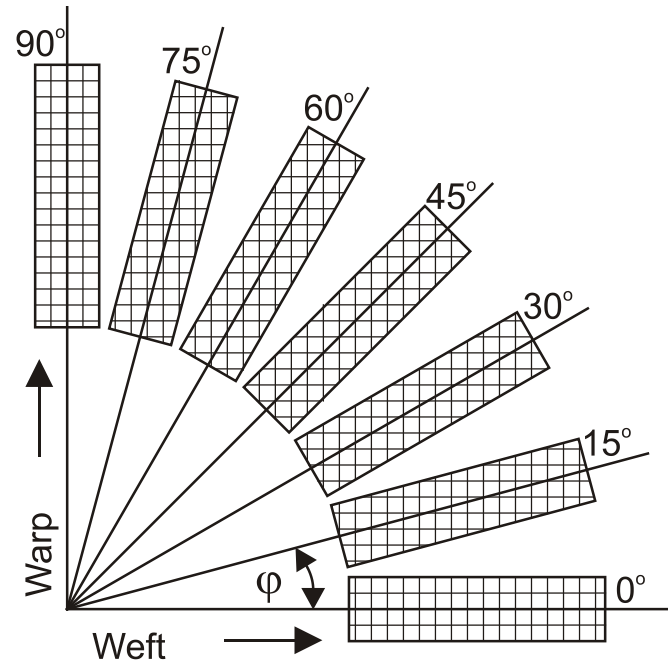

Figure 4. Schematic view of directions (angles) of cutting specimens

For accurate recording and measurement of spatial deformation of fabric a $1 \times 1$ grid pattern was mounted on the tensile tester immediately behind the test specimen; the whole process of drawing the specimen till rupture was recorded by the Panasonic NV-GS500 Digital Video Camera placed on the tripod in front of the device as shown in Figure 5. A digital video camera with a resolution of $720 \times 576$ pixels, and with a recording speed of $\mathrm{N}_{\mathrm{sl}}=25$ frames / $\mathrm{s}$ was used and is connected to the computer via an IEEE 1394 (FireWire) interface. The horizontal distance between the camera and the sample is such that $1 \mathrm{~mm}$ on the grid amounted to 10 pixels on the picture. Two sources of white light which mutually close an angle of $90^{\circ}$ were used for measuring. The number of images $\mathrm{N}$ at a certain extension is:

$$
N=\frac{\varepsilon \cdot l_{0}}{100} \cdot \frac{60}{\mathrm{~V}} \cdot N_{s l}
$$

All the footage was stored on the computer's hard disk in MPEG-2 format. The width of each sample was measured in three spots in order to ensure a higher accuracy of the measured transverse and longitudinal strains. The tensile tester and the camera are connected to a special assembly with simultaneous on/off which fully ensures the exactness of video recording of the entire process of stretching the fabric to rupture. The transverse strain is obtained after all samples were recorded by camera, and the mentioned grid pattern enables fast and accurate editing of the footage processed by the software package Adobe Premiere. Raster individual images were processed in Adobe Photoshop program, Figure 5. Fabric dimensions were measured in pixels, and dimension changes were calculated using Excel software.

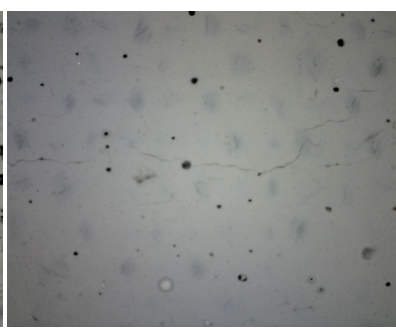

L2

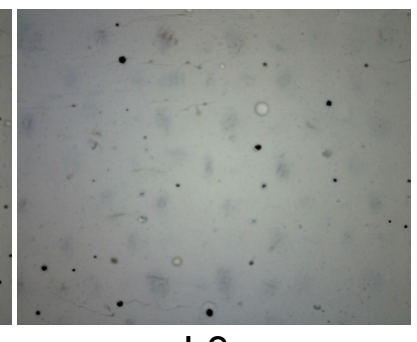

L3

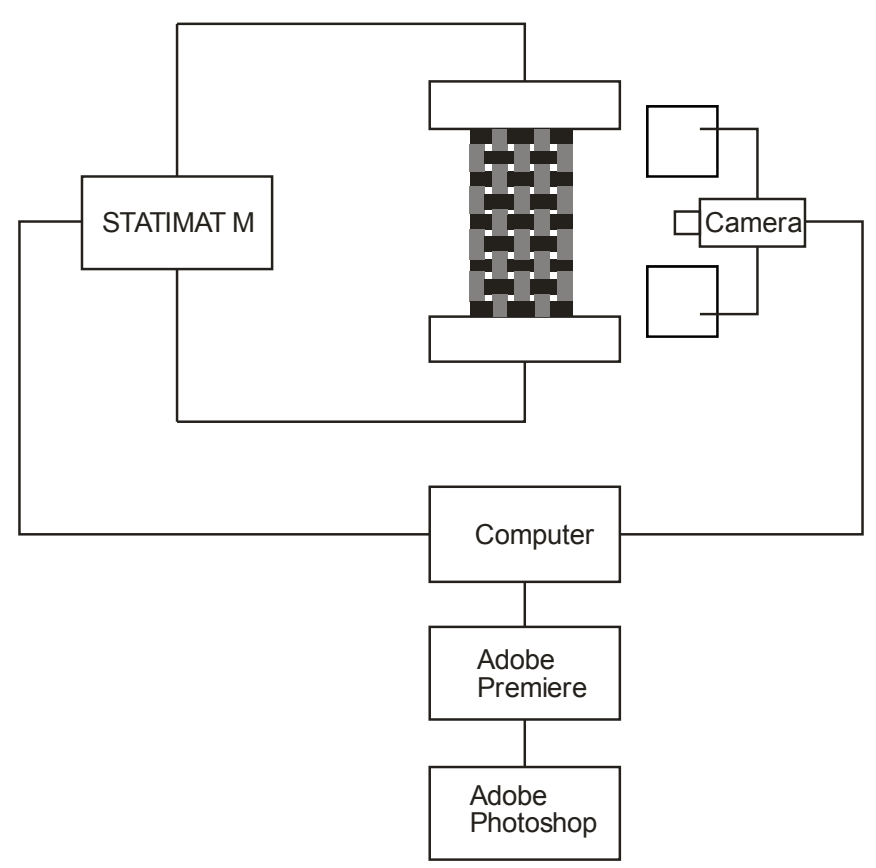

Figure 5. Schematic view of the experiment

\subsection{Overview of test results}

Diagrams $(F-\varepsilon)$ of mean values of test results of the action of tensile force $F$ and the corresponding longitudinal strain (extension) $\varepsilon$ for samples that are cut at different angles to the direction of the weft are shown in Figures 6-9.

The related mean values of tensile force $F_{\varphi}(\mathrm{N})$, extension $\varepsilon$ at break $\varepsilon_{\varphi}(\%)$ and work to rupture $W_{\varphi}(\mathrm{Nm})$ are given in Table 1 in all directions of cutting samples LO, L1, L2, L3.

The polar diagram is a two-dimensional coordinate system in which each point is determined by a distance from a fixed point (pole 0) and an angle from a fixed direction. The distance from the pole is called radial coordinate or radius, and the angle is angular coordinate or polar angle. The radial coordinates represent the mean values of longitudinal strain (extension at break) $\varepsilon_{\varphi}$ in dependence on the cutting direction of the samples, Figure 10 .

The values of extension at break, Figure 10, increase from the weft direction $\left(\varphi=0^{\circ}\right)$ towards the angle of $15^{\circ}$, and after this angle the values of the extension at break grow rapidly and have a maximum value at an angle of $45^{\circ}$. With further increasing the angle $\varphi$, values $\varepsilon_{\varphi}$ rapidly fall from the angle of $45^{\circ}$ towards the angle of $75^{\circ}$. After that angle, 


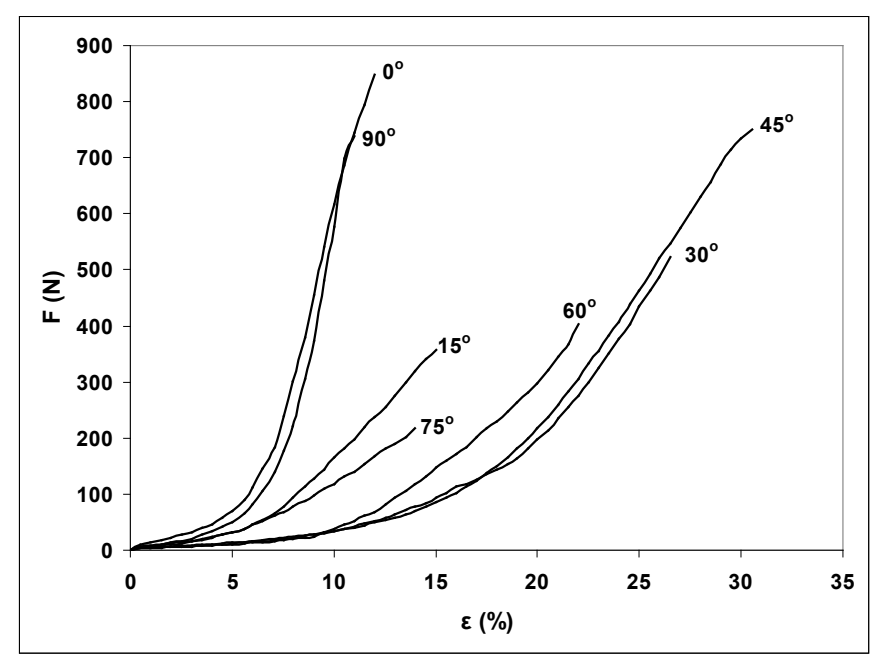

Figure 6. Diagram F- $\varepsilon$ (tensile force extension) for sample L0

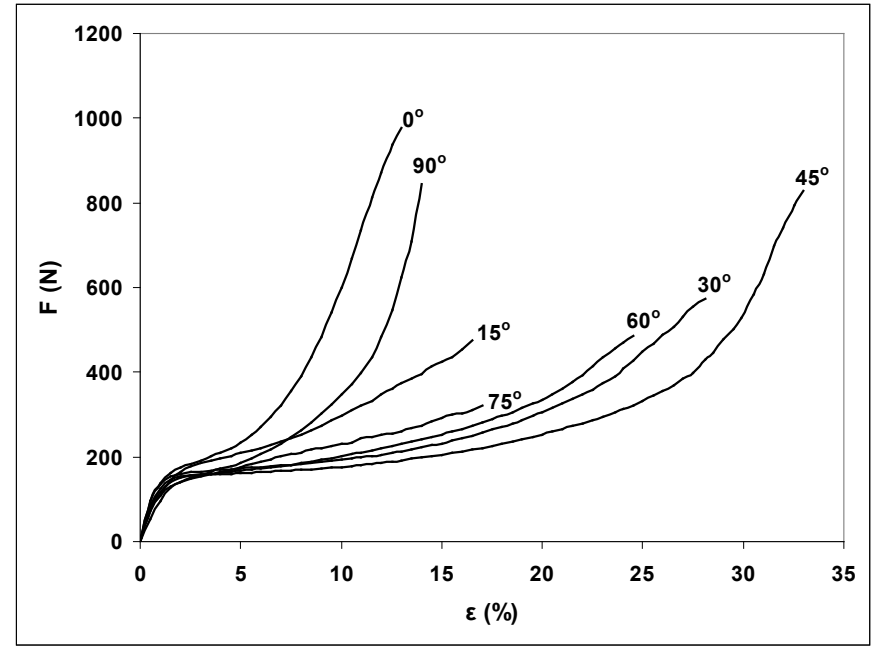

Figure 7. Diagram F- $\varepsilon$ (tensile force- extension) for sample L1

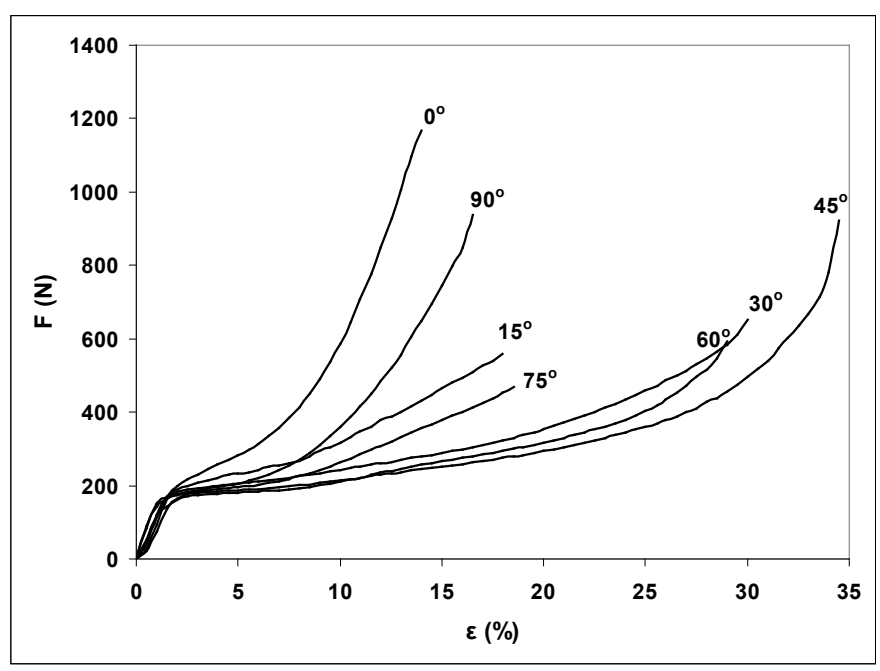

Figure 8. Diagram F- $\varepsilon$ (tensile force-extension) for sample L2

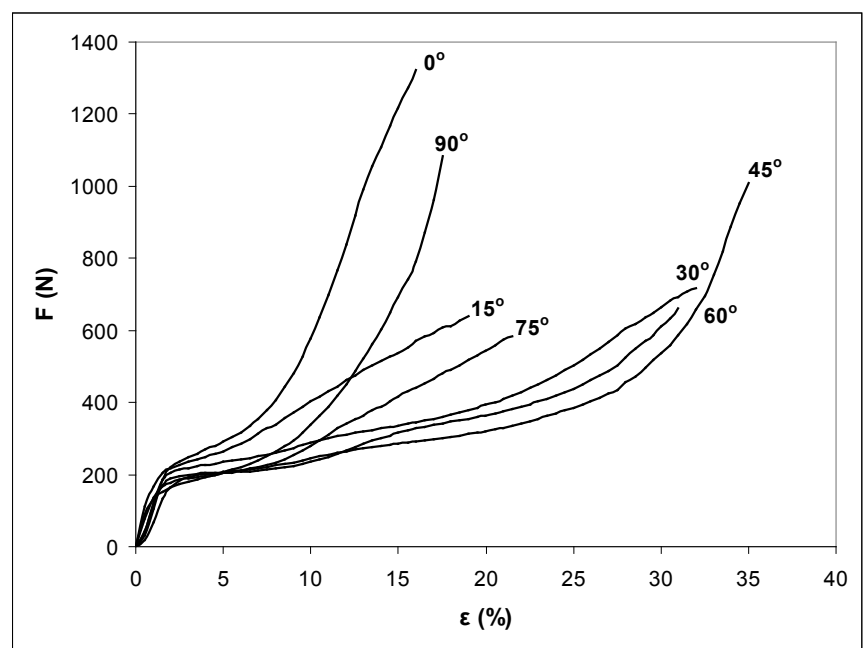

Figure 9. Diagram F- $\varepsilon$ (tensile force-extension) for sample L3

Table 1. Mean values of breaking force, corresponding extension at break and work to rupture

\begin{tabular}{|c|c|c|c|c|c|c|c|c|c|c|c|c|}
\hline & \multicolumn{3}{|c|}{ L0 } & \multicolumn{3}{c|}{ L1 } & \multicolumn{3}{c|}{ L2 } & \multicolumn{3}{c|}{ L3 } \\
\hline$\varphi\left({ }^{\circ}\right)$ & $\varepsilon_{\varphi}$ & $F_{\varphi}$ & $W_{\varphi}$ & $\varepsilon_{\varphi}$ & $F_{\varphi}$ & $W_{\varphi}$ & $\varepsilon_{\varphi}$ & $F_{\varphi}$ & $W_{\varphi}$ & $\varepsilon_{\varphi}$ & $F_{\varphi}$ & $W_{\varphi}$ \\
\hline 0 & 12.24 & 858.2 & 6.28 & 12.94 & 977.8 & 9.07 & 14.21 & 1170.2 & 10.74 & 15.89 & 1321.1 & 12.12 \\
\hline 15 & 15.04 & 359.1 & 1.21 & 16.41 & 474.2 & 4.22 & 17.71 & 558.6 & 7.38 & 18.91 & 638.8 & 9.52 \\
\hline 30 & 26.32 & 523.0 & 6.84 & 28.87 & 572.5 & 11.93 & 29.31 & 648.4 & 15.51 & 32.26 & 718.6 & 20.12 \\
\hline 45 & 30.62 & 751.2 & 12.51 & 33.17 & 828.0 & 22.64 & 34.48 & 922.7 & 27.68 & 37.92 & 1010.1 & 29.97 \\
\hline 60 & 21.82 & 404.2 & 4.22 & 24.66 & 485.8 & 7.88 & 28.82 & 594.9 & 16.89 & 31.28 & 660.6 & 19.84 \\
\hline 75 & 14.18 & 212.4 & 3.25 & 16.91 & 320.5 & 7.11 & 18.54 & 467.9 & 10.04 & 21.37 & 582.2 & 14.55 \\
\hline 90 & 10.94 & 764.9 & 6.80 & 13.76 & 842.2 & 10.26 & 16.18 & 937.7 & 13.19 & 17.13 & 1082.8 & 15.45 \\
\hline
\end{tabular}


the extension at break slightly decreases, up to the warp direction $\left(\varphi=90^{\circ}\right)$.

The mean values of breaking forces $F_{\varphi}$ in dependence on the cutting direction of the samples is shown by the polar diagram in Figure 11a. In the polar diagram, Figure 11b, the radial coordinates represent the mean values of work to rupture $W_{\varphi}$ in dependence on the cutting direction of the samples.

When the number of layers increasing, the values of extensions at break, breaking forces and work to rupture also increase.

The cutting direction of the samples affects the value of breaking force and the strength of textile materials. The highest breaking force for all samples is in the weft direction $\varphi=0^{\circ}$, followed by the direction of warp $\varphi=90^{\circ}$, and at an angle of $45^{\circ}$, Figure 11a. This is explained by the fact that in weaving warp yarns are more strained than weft yarns. The values of the breaking forces of the tested samples that are cut in other directions are lower, because the number of yarns that are simultaneously caught in both clamps of the tensile tester decreases. For the complementary angles of $15^{\circ}$ and $75^{\circ}$ breaking force values are lower than for complementary angles of $30^{\circ}$ and $60^{\circ}$, because the direction of the force and pinned yarns coincide, then neither are drawn almost at a straight line. For an angle of $45^{\circ}$ breaking force increases as compared to the angles $15^{\circ}, 30^{\circ}, 60^{\circ}$ and $75^{\circ}$, because the direction of the force does not coincide with the direction of the threads therefore require more force. Work to rupture $\mathrm{W}_{\varphi}$ was calculated in order to characterize breaking properties of the sample in the area of higher strain. From the results shown in Figure $11 \mathrm{~b}$ it can be seen that samples $L 2$ and L3 have the highest values of work to rupture. Minimum energy is needed for sample L0. This sample has the lowest work to rupture and it is the weakest for taking over tensile force.

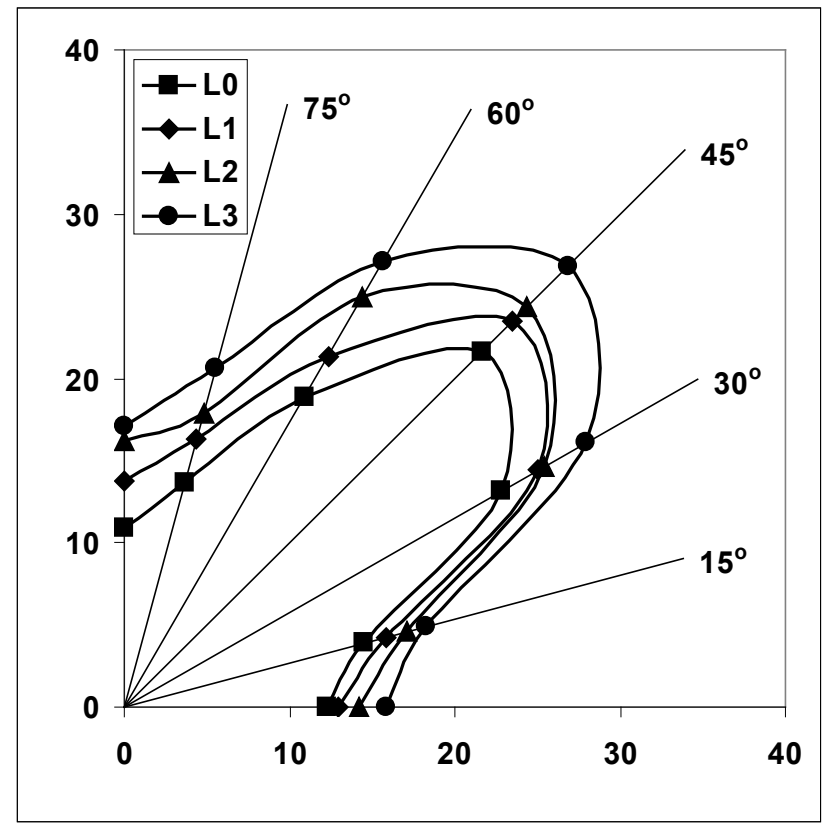

Figure 10. Polar diagram of the experimentally obtained values of extension at break $\varepsilon_{\varphi}(\%)$

According to equation (8) and based on the experimentally obtained values of breaking forces $F_{\varphi}$, extension at break $\varepsilon_{\varphi}$ and work to rupture $W_{\varphi}$ in Table 1 , the values of the coefficients of anisotropy of breaking forces $K_{A F}$, extension at break $K_{A \varepsilon}$ and work to rupture $K_{A W}$ were calculated. The calculated values $K_{A i}$ are shown in Table 2.

According to the results in Table 2, sample L0 has the highest coefficients of anisotropy $K_{A \varepsilon}, K_{A F}, K_{A W}$ and their values decrease with the number of layers.

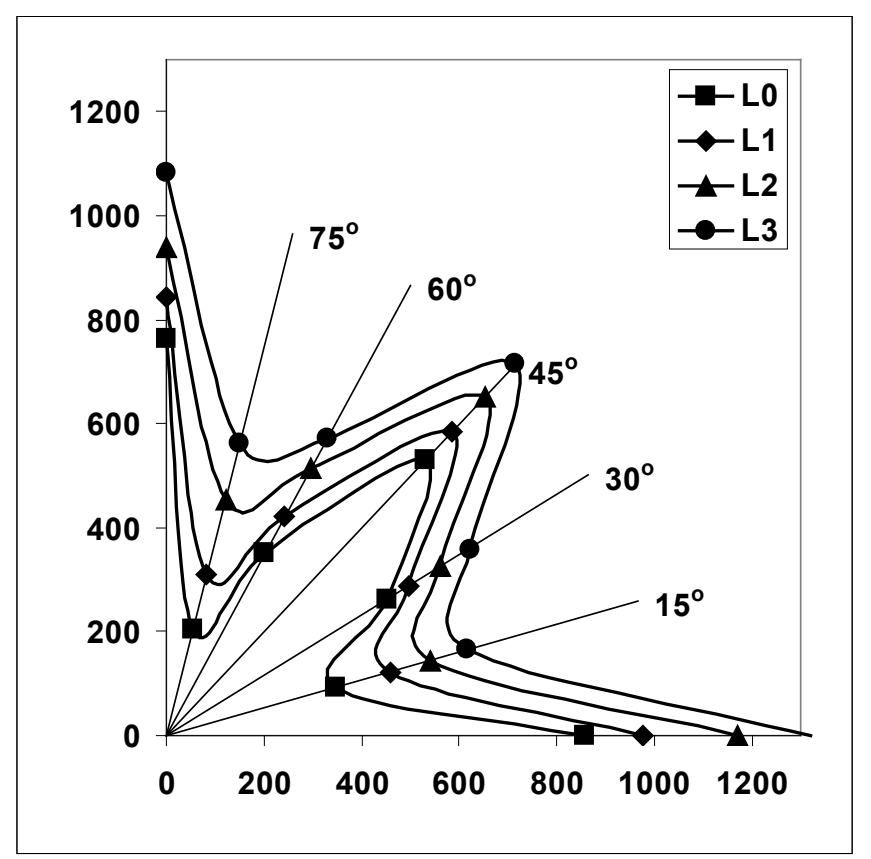

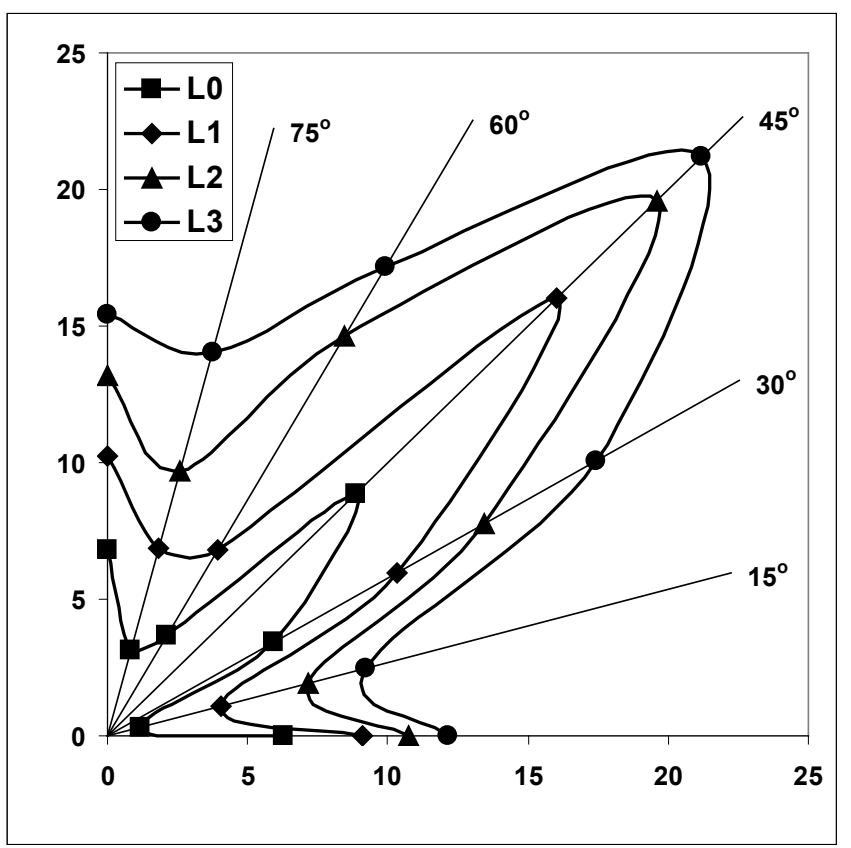

Figure 11. Polar diagrams of the experimentally obtained values in dependence on the cutting direction of the samples: a) breaking force $F_{\varphi}(N)$, b) work to rupture $W_{\varphi}(\mathrm{Nm})$ 
Table 2. Coefficients of anisotropy $\mathrm{K}_{\mathrm{Ai}}$ for experimental data $\varepsilon_{\varphi}, \mathrm{F}_{\varphi}, \mathrm{W}_{\varphi}$

\begin{tabular}{|c|c|c|c|}
\hline & $\mathbf{K}_{\mathrm{A \varepsilon}}$ & $\mathbf{K}_{\mathrm{AF}}$ & $\mathbf{K}_{\mathrm{AW}}$ \\
\hline $\mathrm{L} 0$ & 2.80 & 4.04 & 10.34 \\
\hline L1 & 2.56 & 3.05 & 5.37 \\
\hline L2 & 2.43 & 2.50 & 3.75 \\
\hline L3 & 2.39 & 2.27 & 3.15 \\
\hline
\end{tabular}

The final states of tested samples L0, L1, L2 and L3 with 50x increasing when the samples are cut in the weft direction $\left(\varphi=0^{\circ}\right)$, at an angle of $45^{\circ}$ and in the warp direction $\left(\varphi=90^{\circ}\right)$ are shown in Figure 12. Cracks of the applied coating in the weft direction $\left(\varphi=0^{\circ}\right)$ and warp direction $\left(\varphi=90^{\circ}\right)$ are always perpendicular to the direction of force, while at an angle of $45^{\circ}$ cracks of the applied coating have undefined direction due to a change in the angle of crossing between the warp and weft thread system. When samples are elongated in the direction that is not in the warp or weft direction, yarns have shear stress in the early stages. All the tested samples had a point of breaking in the middle of the sample or along the clamps; thus, the state of the sample was recorded with the microscope at a distance of $1 / 4$ of the clamped sample length from the bottom clamp.

\section{Determining the initial modulus of elasticity}

Based on the experimentally obtained force-extension curves, the values of the initial modulus of elasticity were obtained and compared with the corresponding calculated values. Deviation in the percentage between the experimental and calculated values of the initial modulus of elasticity will also be calculated.

\subsection{Experimental values of the initial modulus of elasticity}

From the presented diagrams, in Figures 6-9, the values of tensile force in the elastic range are used. We determined the modulus of elasticity $E_{\varphi}$ from a particular region on the force - extension curve $(F-\varepsilon)$ that is determined by monitoring the experimental data obtained from an experimental set-up with regression control chart [20]. In this area, the relationship between stress and strain is linear. The modulus of elasticity $E_{\varphi}$ is defined as a slope of its stress-strain curve in the elastic deformation region.
L1
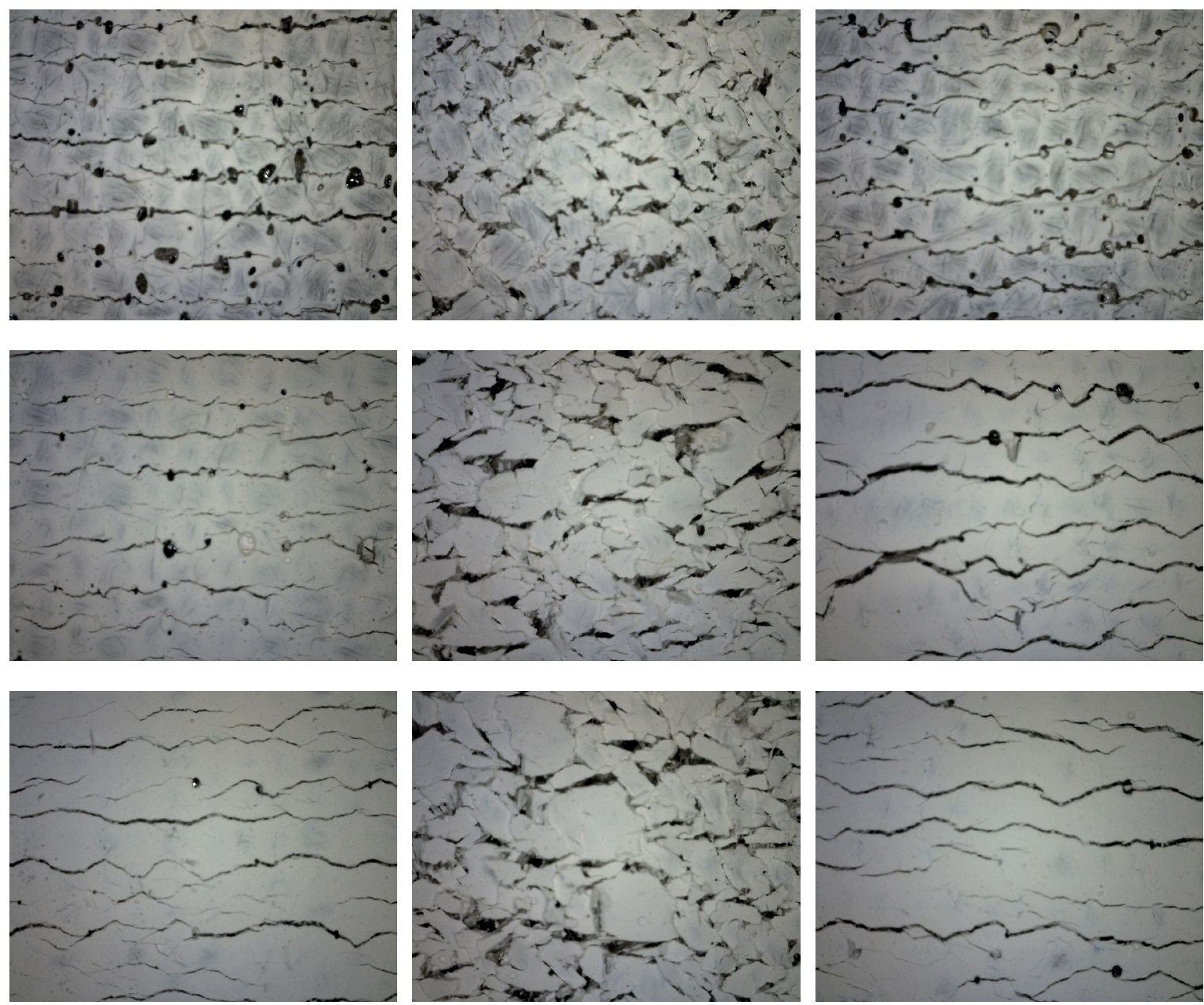

$\varphi=0^{\circ}$

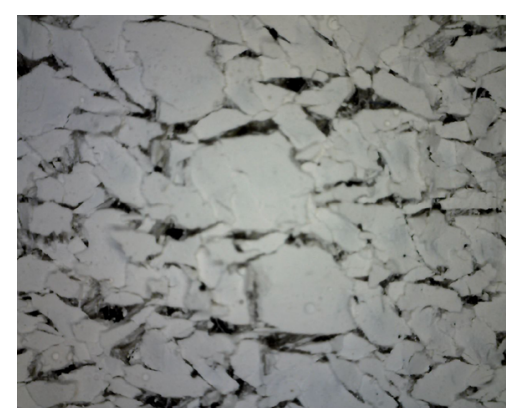

$\varphi=45^{\circ}$

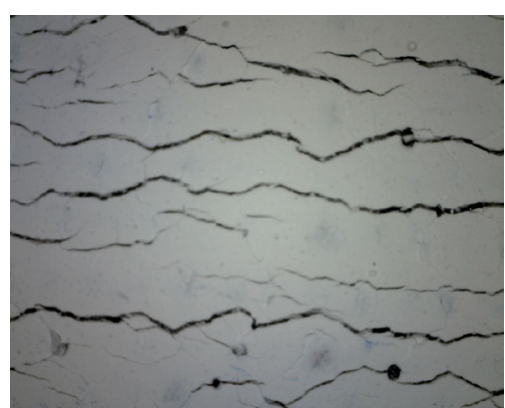

$\varphi=90^{\circ}$

Figure 12. Condition of tested samples L0, L1, L2, L3, immediately after breaking by $50 x$ increase when the samples were cut at angles $0{ }^{\circ}, 45^{\circ}$, $90^{\circ}$ 
Hooke's law for uniaxial stress can be applied:

$$
E_{\varphi}=\operatorname{tg} \alpha=\frac{\sigma}{\varepsilon}=\frac{F}{\varepsilon \cdot b \cdot d}[P a]
$$

where $b$ is the width, and $d$ thickness of the sample.

Using values $F$ and $\varepsilon$ in the elastic range and using equation (14), the mean values of the initial modulus of elasticity $E_{\varphi}$ in relation to an arbitrary direction of cutting fabric samples are calculated. Linear regression equations are placed on the stress-strain curves in the elastic range. The slope of the curve, that is, the coefficient of line direction represents the modulus of elasticity $E_{\varphi}[24]$.

The obtained experimental values of the modulus of elasticity $E_{\varphi}$ in dependence on a change in the cutting angle of the samples are given in Table 3. The polar diagram of experimental values $E_{\varphi}$ for each $15^{\circ}$ is shown in Figure 13.

Experimental values of the modulus of elasticity $E_{\varphi}$ increase with the number of layers. Sample LO has the highest module of elasticity in the warp and weft direction. The differences between the values of $E_{\varphi}$ for samples L1, L2 and L3 in different directions decrease. The smallest difference between the values of the modulus of elasticity $E_{\varphi}$ for different directions is for sample L3, which has the highest number of layers on raw canvas.

\subsection{Calculation of the initial modulus of elasticity in relation to an arbitrarily selected coordinate system}

According to equation (7) and based on the experimental data $E_{0^{\circ}}=E_{x^{\prime}}, E_{90^{\circ}}=E_{y}$ and $E_{45^{\circ}}$ in Table 3, the values of the modulus of elasticity $E_{\varphi}$ were calculated, depending on a change in the cutting angle of the samples. The calculated values of $E_{\varphi}$ for each $15^{\circ}$ are shown in Table 4.

The polar diagram of their calculated values $E_{\varphi}(\mathrm{kPa})$ for each $5^{\circ}$ is shown in Figure 14.

Table 5 shows deviations in percentage between experimental values $E_{\varphi}$ in Table 3 and calculated values $E_{\varphi}$ in Table 4 . Deviations $D(\%)$ are calculated using the expression (15):

$$
D=\frac{E_{\varphi, e k s}-E_{\varphi, c a l c}}{E_{\varphi, e k s}} \cdot 100(\%)
$$

In the warp $\left(90^{\circ}\right)$ and weft $\left(0^{\circ}\right)$ directions and at an angle of $45^{\circ}$, differences in percentage between experimental and calculated values of the initial modulus of elasticity $E_{\varphi}$ are $0 \%$. It follows from equation (7) due to the periodicity of the sin and cos functions for these values. Negative deviation values show that the obtained calculated values $E_{\varphi}$ are higher than the experimental values of $E_{\varphi}$. With the increase of the number

Table 3. Experimentally obtained values of the modulus of elasticity $\mathrm{E}_{\varphi}(\mathrm{kPa})$

\begin{tabular}{|c|c|c|c|c|c|c|c|}
\hline Sample & $\mathbf{E}_{0^{\circ}}$ & $\mathbf{E}_{15^{\circ}}$ & $\mathbf{E}_{30^{\circ}}$ & $\mathbf{E}_{45^{\circ}}$ & $\mathbf{E}_{\mathbf{6 0}^{\circ}}$ & $\mathbf{E}_{\mathbf{7 5}^{\circ}}$ & $\mathbf{E}_{90^{\circ}}$ \\
\hline L0 & 324.2 & 146.6 & 59.8 & 76.6 & 56.8 & 150.4 & 171.7 \\
\hline L1 & 5098.2 & 4421.6 & 3128.5 & 4365.9 & 3212.7 & 3800.2 & 4058.7 \\
\hline L2 & 6116.2 & 5344.6 & 5378.5 & 5211.3 & 4490.2 & 4508.5 & 4911.2 \\
\hline L3 & 7279.8 & 7058.2 & 6607.5 & 5986.2 & 5421.1 & 5646.9 & 6001.2 \\
\hline
\end{tabular}

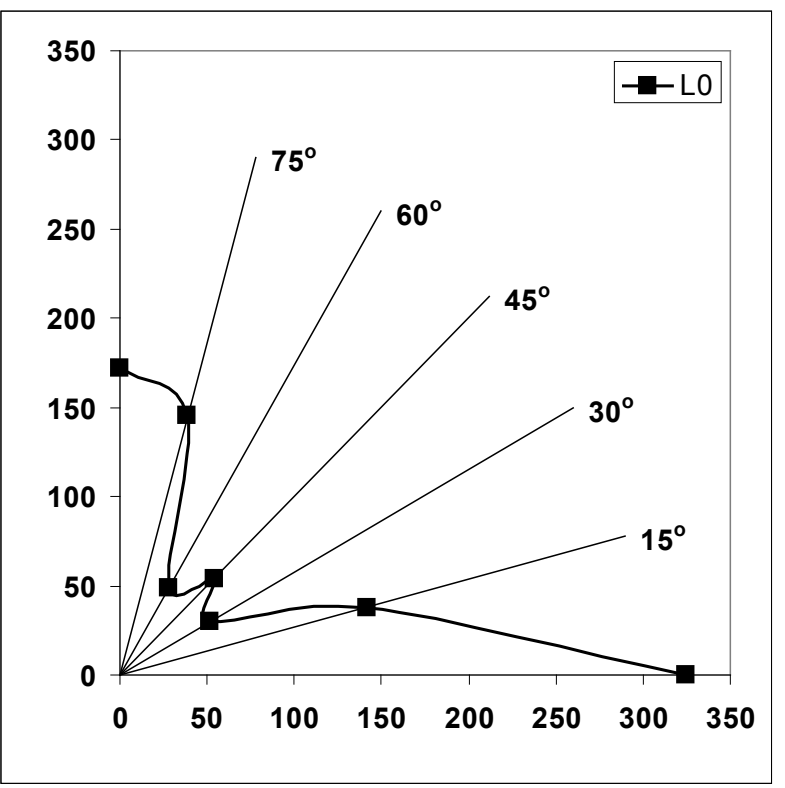

a.

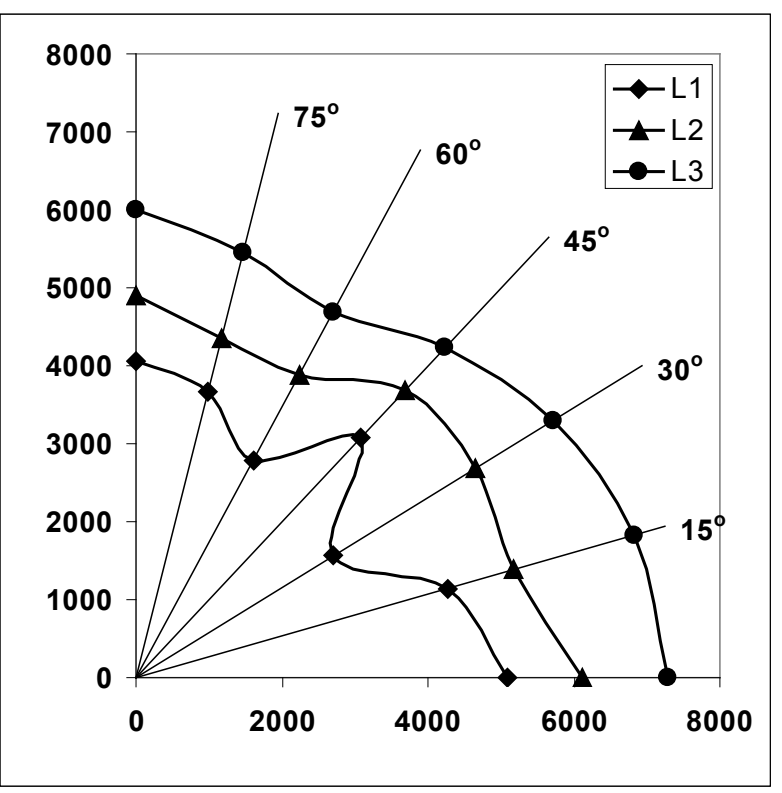

b.

Figure 13. The polar diagram of experimental values of the modulus of elasticity $E_{\varphi}(k P a)$ for each $\left.\left.15^{\circ}: a\right) L 0, b\right) L 1, L 2, L 3$ 
Table 4. The calculated values of the modulus of elasticity $\mathrm{E}_{\varphi}(\mathrm{kPa})$

\begin{tabular}{|c|c|c|c|c|c|c|c|}
\hline Samples & $\mathbf{E}_{\mathbf{0}^{\circ}}$ & $\mathbf{E}_{\mathbf{1 5}^{\circ}}$ & $\mathbf{E}_{\mathbf{3 0 ^ { \circ }}}$ & $\mathbf{E}_{\mathbf{4 5 ^ { \circ }}}$ & $\mathbf{E}_{\mathbf{6 0 ^ { \circ }}}$ & $\mathbf{E}_{\mathbf{7 5}^{\circ}}$ & $\mathbf{E}_{\mathbf{9 0}^{\circ}}$ \\
\hline L0 & 324.2 & 184.5 & 97.8 & 76.6 & 86.3 & 128.3 & 171.7 \\
\hline L1 & 5098.2 & 4963.8 & 4661.1 & 4365.9 & 4172.6 & 4082.2 & 4058.7 \\
\hline L2 & 6116.2 & 5942.8 & 5562.4 & 5211.3 & 5004.1 & 4925.8 & 4911.2 \\
\hline L3 & 7279.8 & 6988.6 & 6411.4 & 5986.2 & 5861.5 & 5937.0 & 6001.2 \\
\hline
\end{tabular}

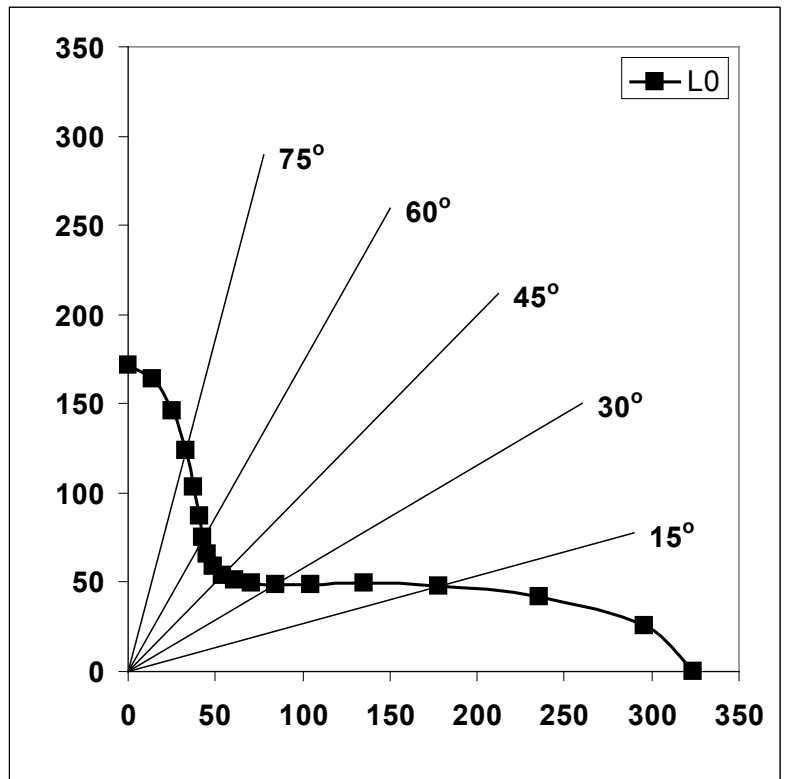

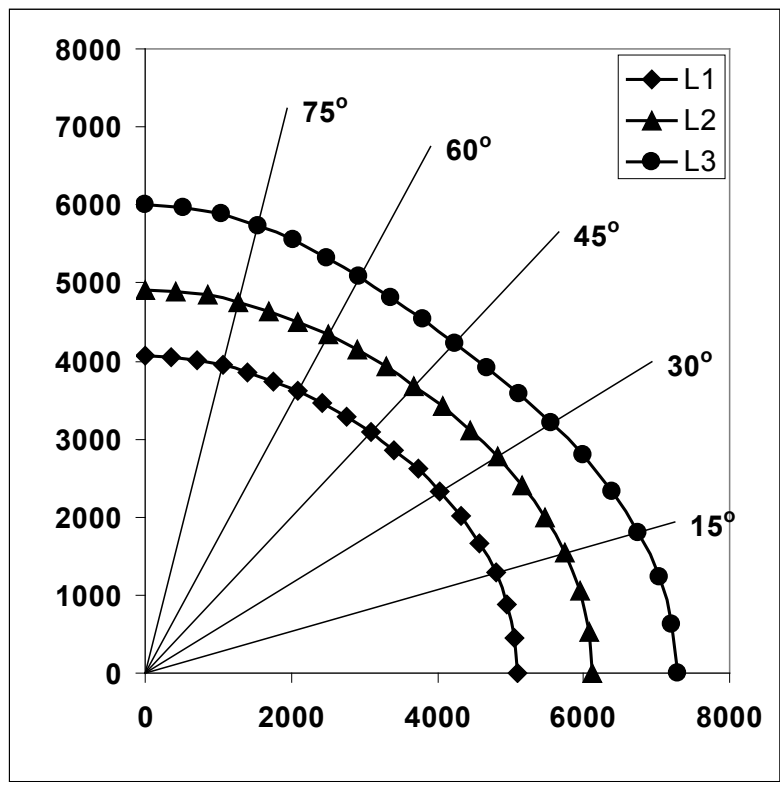

b.

Figure 14. The polar diagram of calculated values of modulus of elasticity $E_{\varphi}(k P a)$ for each $\left.\left.5^{\circ}: a\right) L 0, b\right) L 1, L 2, L 3$

Table 5. Deviations $\mathrm{D}$ in (\%) between experimental values and calculated values $\mathrm{E}_{\varphi}$

\begin{tabular}{|c|c|c|c|c|c|c|c|}
\hline Samples & $\mathbf{0}^{\circ}$ & $\mathbf{1 5}^{\circ}$ & $\mathbf{3 0}^{\circ}$ & $\mathbf{4 5}^{\circ}$ & $\mathbf{6 0}^{\circ}$ & $\mathbf{7 5}^{\circ}$ & $\mathbf{9 0}^{\circ}$ \\
\hline L0 & 0 & -25.89 & -63.46 & 0 & -51.82 & 14.67 & 0 \\
\hline L1 & 0 & -7.80 & -48.99 & 0 & -29.88 & -7.42 & 0 \\
\hline L2 & 0 & -11.19 & -3.42 & 0 & -11.44 & -9.26 & 0 \\
\hline L3 & 0 & 0.99 & 2.97 & 0 & -8.12 & -5.14 & 0 \\
\hline
\end{tabular}

of layers, deviations between experimental and computational values of the modulus of elasticity decrease. For sample L3 deviations are minimal.

According to equation (8) and based on the experimental data $E_{\varphi}$ from Table 3, the values of coefficients of anisotropy $K_{A E}-\exp$. were calculated and their values are shown in Table 6. According to equation (8) and based on the calculated values of $E_{\varphi}$ from Table 4 , the values of coefficients of anisotropy $K_{A E}-$ calc. were calculated and their values are also shown in Table 6.

Table 6. Coefficients of anisotropy for experimental and calculated values $\mathrm{E}_{\varphi}$

\begin{tabular}{|c|c|c|}
\hline & $\mathbf{K}_{\mathrm{AE}}-\mathbf{e x p .}$ & $\mathbf{K}_{\mathrm{AE}}-$ calc. \\
\hline L0 & 5.71 & 4.23 \\
\hline $\mathrm{L} 1$ & 1.63 & 1.26 \\
\hline L2 & 1.36 & 1.25 \\
\hline L3 & 1.34 & 1.24 \\
\hline
\end{tabular}

The coefficient of anisotropy of the modulus of elasticity $K_{A E}$ decreases with increasing number of layers. When reducing material anisotropy, the values of the modulus of elasticity $E_{\varphi}$ are placed on the curve which approaches the quarter of circle, which is a characteristic of isotropic materials. It can be concluded from the diagrams in Figures 13 and 14. Therefore, with a change in the number of layers mechanical properties of the material change too.

When increasing the number of layers, the values of the modulus of elasticity also increase. Additionally, with increasing number of layers, the values of breaking force, extension at break and work to rupture in the direction of warp $\left(\varphi=90^{\circ}\right)$ and weft $\left(\varphi=0^{\circ}\right)$ also increase.

\section{Determination of Poisson's ratio}

The fabric sample width is $b_{0}=500$ pixels, which is equivalent to $b_{0}=50 \mathrm{~mm}$. Upon reading the value of the fabric width after 
the action of force, relative transverse strain is calculated using equation (12). The action of tensile force on canvas samples that were cut in warp or weft direction causes the internal interaction between weft and warp yarns. Because of that fabric contraction in the transverse direction, that is, in the direction which is perpendicular to the direction stretching occurs. Due to this phenomenon, it comes to the loss of the rectangular shape of the sample, that is, there is a contraction of the fabric sample.

The relation between the continuous change of relative contraction $s(\%)$ of the sample and its relative extension $\varepsilon(\%)$ when a force acts on samples that are cut in the weft direction is shown in Figure 15 with a characteristic curve. Figure 16 shows a characteristic curve of relative contraction of the sample in relation to its relative extension when the force acts on samples that are cut in the warp direction.

When a force acts on samples that are cut in the weft direction, at the same relative extension $\varepsilon$, the coated fabric with the highest number of coated layers (L3) has the lowest relative contraction, and raw fabric (LO) has the highest relative contraction s, Figure 15.

When a force acts on samples that are cut in the warp direction, at the same relative extension $\varepsilon$, the coated fabric with the highest number of coated layers (L3) has the lowest relative contraction, and raw fabric (LO) has the highest relative contraction s, Figure 16. From diagrams in Figures 15 and 16 it is evident that fabric contractions are small at the beginning of stretching. After that, with an increase in stretching, the values of fabric contraction also increase. According to equation (13) and based on the experimental values of relative contraction $s$ and relative extension $\varepsilon$ from Figure 15, the values of Poisson's ratio $v$ are calculated when the force acts on samples that are cut in the weft direction. Figure 17 shows a curve of the values of the Poisson's ratio $v$ in relation to its relative extension when the force acts on samples that are cut in the weft direction.

According to equation (13) and based on the experimental values of relative contraction $s$ and relative extension $\varepsilon$ from Figure 16, the values of Poisson's ratio $v$ are calculated when the force acts on the samples that are cut in the warp direction. Figure 18 shows a curve of the values of the Poisson's ratio $v$ in relation to its relative extension when the force acts on the samples that are cut in the warp direction.

The shape of the Poisson's ratio curve for canvas is a result of internal interactions in the coated and raw fabrics. A change in the values of relative contraction of painting canvases shown in Figures 15 and 16 affects the shape of the Poisson's ratio curve, Figures 17 and 18. When the force acts on samples that are cut in the weft direction, Poisson's ratio assumes maximum value at the relative extension of painting canvases between 9 and $10 \%$, Figure 17 . When the force acts on samples that are cut in the warp direction, Poisson's ratio assumes the maximum value at relative extension of painting canvases around $15 \%$, Figure 18. In weft direction, the values of Poisson's ratio of painting canvas decrease with increasing the number of coated layers at the same relative extension, Figure 17. In warp direction, the values of Poisson's ratio of painting canvas increase with increasing the number of coated layers at the same relative extension, Figure 18.

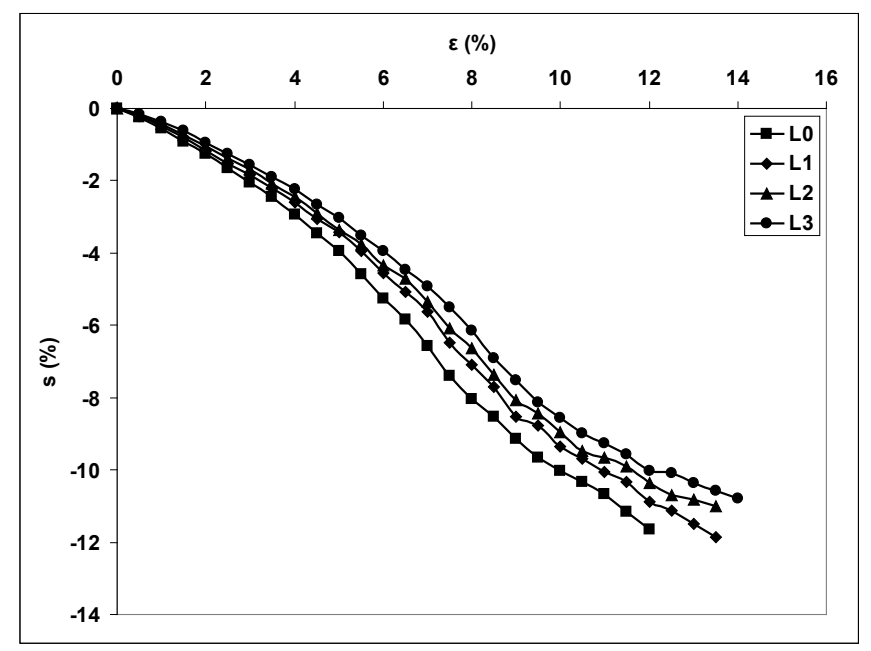

Figure 15. Diagram of relative contraction of fabric s (\%) when the force acts on samples that are cut in the weft direction

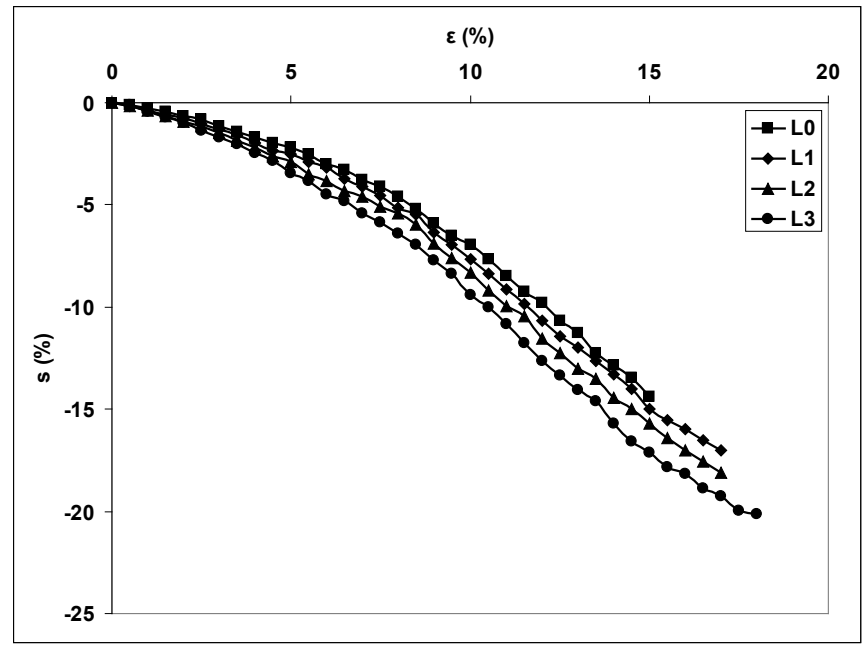

Figure 16. Diagram of relative contraction of fabric s (\%) when the force acts on samples that are cut in the warp direction

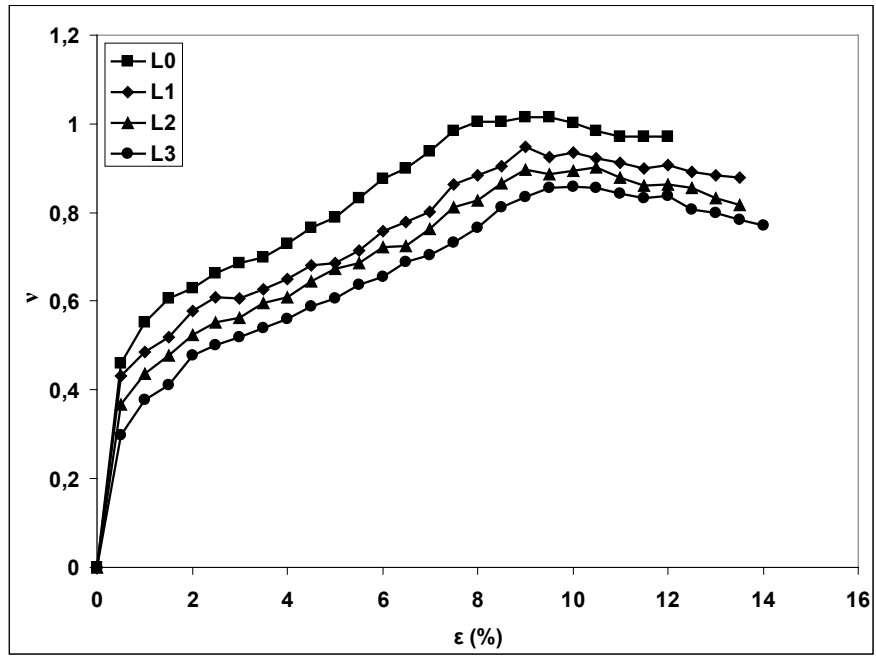

Figure 17. Poisson's ratio of the fabric $v$ when the force acts on samples that are cut in the weft direction 


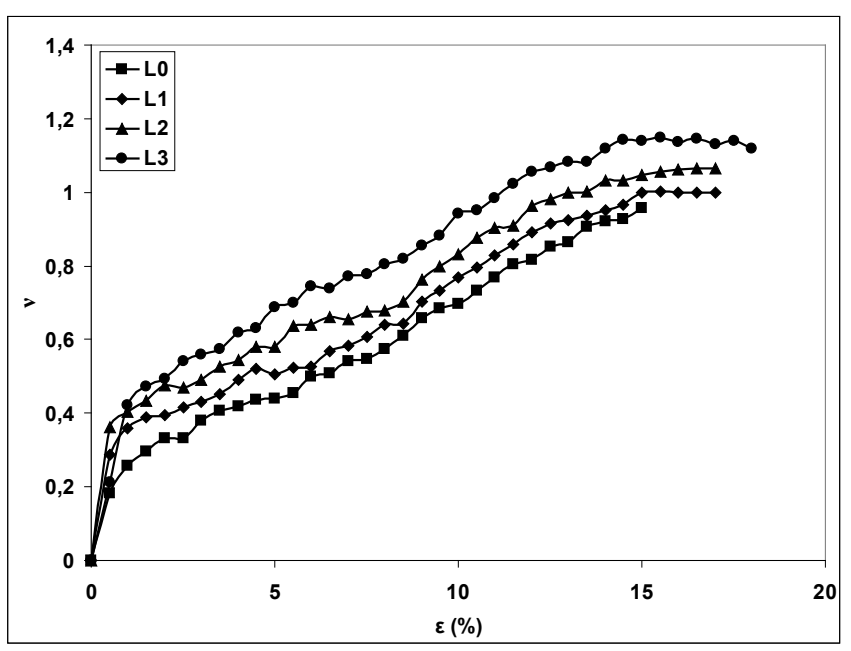

Figure 18. Poisson's ratio of the fabric $v$ when the force acts on samples that are cut in the warp direction

\section{Conclusions}

Canvas is a coated material which can be defined as elastic orthotropic material with two axes of orthotropy. For calculating the modulus of elasticity in the linear range when tensile force acts on samples that are cut in arbitrary directions Hooke's law for anisotropic material behaviour can be applied. The values of breaking force, extension at break, work at break and modulus of elasticity are changing in dependence on the cutting direction of the sample.

Based on the experimentally obtained values $E_{0^{\circ},} E_{90^{\circ}}$ and $E_{45^{\circ}}$, the modulus of elasticity can be approximately determined by mathematical expression when a force acts on samples that are cut in various directions. Deviations between experimental and theoretical values of the initial modulus of elasticity decrease with increasing the number of layers. Mechanical properties of textile materials are significantly improved by applying several coated layers. Therefore, the canvas has significantly improved properties compared to the initial basic material (substrate). By increasing the number of layers of painting canvases coefficients of anisotropy, modulus of elasticity, breaking forces, elongation at break and work at break decrease. It can be concluded that with increasing the number of layers, anisotropy of materials decreases and painting canvas assumes the characteristics of an isotropic material. The values of the modulus of elasticity increase with increasing the number of coating layers. Due to different influences, such as temperature, relative moisture, structure of the substrate and applied coatings, as well as the number of coatings, there is a difference between experimental and calculated values of the modulus of elasticity. Deviations of experimental and calculated values of the initial modulus of elasticity decrease with increasing the number of coatings. With increasing the number of layers on painting canvas, a better agreement between experimental results and the calculated values of the modulus of elasticity is achieved. Thus, theoretical equations can be used with a high accuracy to calculate the modulus of elasticity of painting canvas in various directions. Therefore, the measurements need to be implemented when tensile force acts on samples that are cut in the warp and weft direction and at an angle of $45^{\circ}$.
Due to the anisotropy of painting canvases, Poisson's ratio is not constant, but varies with each fabric extension. Behaviour and shape of Poisson's ratio curve of the painting canvas that is subjected to tensile force, mostly depends on its behaviour in a direction perpendicular to extension. Poisson's ratio values depend on the number of coatings applied to the raw fabric.

The results obtained by these tests are just to understand the breaking properties of coated fabrics and applicability of theoretical equations for calculating the initial modulus of elasticity, which can help predict the behaviour of such fabrics when stretching.

\section{ACKNOWLEDGEMENTS}

This work was supported by the institutional research program initiated by the Faculty of Textile Technology, University of Zagreb.

\section{References}

[1] Bao, L., et al. (1997). Error Evaluation in Measuring the Apparent Possion's Ratios of Textile Fabrics by Uniaxial Tensile Test. Sen'i Gakkaishi, 53(1), 20-26.

[2] Bassett, R. J., et al. (1999). Experiment Methods for Measuring Fabric Mechanical Properties: a Review and Analysis. Textile Research Journal, 69(11), 866-875.

[3] Chen, B., Govindaraj, M., (1996). A Parametric Study of Fabric Drape. Textile Research Journal, 66(1), 17-24.

[4] Clulow, E.E., Taylor, H. M., (1963). An experimental and theoretical investigation of biaxial stress-strain relations in a plain-weave cloth. Journal of the Textile Institute, 54(8), T323-T347.

[5] Cornelius, F.D., (1967). Movement of wood and canvas for paintings in response to high and low $\mathrm{RH}$ cycles. Studies in Conservation, 12(2), 76-79.

[6] Fressl, I. (1966). Slikarska tehnologija. Radionice škole primijenjene umjetnosti (Zagreb).

[7] FuJii, T., (1992). Study on strength and nonlinear stressstrain response of plain woven glass fiber laminates under biaxial loading. Journal of Composite Materials, 26(17), 2493-2510.

[8] Greenwood, K. (1975). Weaving: Control of Fabric Structure. Merrow Technical Library (Shildon).

[9] Hearle, J.W.S. et al. (1969). Structural Mechanics of Yarns and Fabrics. Wiley-Interscience (New York).

[10] Hedley G., (1988). Relative humidity and the stress/strain response of canvas paintings: uniaxial measurements of naturally aged samples. Studies in Conservation, 33(3), 133-148.

[11] Hedley, G., (1981). The stiffness of lining fabrics: theoretical and practical considerations in ICOM Committee for Conservation 6th Triennial Meeting, Ottawa, 81/2/2-1-13.

[12] Kawabata, S., (1973). The finite-deformation theory of plain weave fabrics, Part 1: The biaxial deformation theory. Journal of the Textile Institute, 64(1), 137-149.

[13] Kilby, W. F., (1963). Planar Stress-strain Relationship in Woven Fabrics. Journal of the Textile Institute, 54(1), T9T27. 
[14] Kovar, R., Gupta, B. S., (2009). Study of the Anisotropic Nature of the Rupture Properties of a Plain Woven Fabric. Textile Research Journal, 79(6), 506-516.

[15] Kraigher-Hozo, M. (1991). Slikarstvo/ Metode slikanja/ Materijali. Svjetlost (Sarajevo).

[16] Lekhnitskii, S. G. (1981). Theory of Elasticity of an Anisotropic Elastic Body. Mir Publishers (Moscow).

[17] Lloyd, D. W., et al., (1977). An Examination of a "Wide jaw" Test for the Determination of Fabric Poisson Ratio. Journal of the Textile Institute, 68 (9), 299-302.

[18] Masters, J.E., Ko, F., (1996). Guest editorial. Composites Science and Technology, 56 (3), 205-207.

[19] Michalski S., (1991). Paintings-their response to temperature, relative humidity, shock, and vibration. Art in Transit:: Studies in the Transport of Paintings, ed. M.F. Mecklenburg, National Gallery of Art, Washington, 223249.

[20] Ozkul, B., Karaoglan , D., (2011). Regression control chart for determination of Young's modulus: A case study. Scientific Research and Essays, 6(30), 6393-6403.

[21]Pan, N., (1996). Analysis of woven fabric strengths: prediction of fabric strength under uniaxial and biaxial extensions. Composites Science and Technology, 56(3), 311-327.

[22] Pan, N., Yoon, M-Y., (1996). Structural Anisotropy, Failure Criterion, and Shear Strength of Woven Fabrics. Textile Research Journal, 66(4), 238-244.

[23] Peirce, F. T., (1937). The geometry of cloth structure. Journal of the Textile Institute, 28(3), T45-T96.

[24] Penava Ž. et al., (2014). Influence of anisotropy and yarn count on the modulus of elasticity of weft rib knitted fabric. Tekstil, 63 (9-10), 283-292.
[25] Penava, Ž., et al., (2014). Determination of the Elastic Constants of a Plain Woven Fabrics by Tensile Test in Various Directions. FIBRES \& TEXTILES in Eastern Europe, 22(2) 57-63.

[26] Penava, Ž., Šimić, D., (2012). Analysis of the elastic constants of woven fabrics for at random chosen extension directions. Tekstil, 61(7-12), 169-179.

[27] Russell, W.H., Berger, G.A., (1982). The behaviour of canvas as a structural support for painting in Science and Technology in the Service of Conservation, IIC, London, 139-145.

[28] Sun, H., (2005). On the Poisson's ratios of a woven fabric. Composite Structures 68(4), 505-510.

[29] Turinski, Ž. (1976). Slikarska tehnologija. Turistička štampa (Beograd).

[30] Warren, W.E., (1990). The elastic properties of woven polymeric fabric. Polymer Engineering Science, 30(20) 1309-1313.

[31] Young C. R. T., Hibberd R. D., (1999). Biaxial tensile testing of paintings on canvas. Studies in Conservation, 44, 129-141.

[32] Zheng, J., (2008). Measuring Technology of the Anisotropic Tensile Properties of Woven Fabrics. Textile Research Journal, 78(12), 1116-1123.

[33] Zouari, R., et al., (2010). Experimental and numerical analyses of fabric off-axes tensile test. Journal of the Textile Institute, 101(1), 58-68.

[34] Zweben, C. et al. (1989). Mechanical Behaviour and Properties of Composite Materials. Vol.1, Technomic (Lancaster). 